\title{
Perioperative Outcomes of Roux-en-Y Gastric Bypass and Sleeve Gastrectomy in Patients with Diabetes Mellitus: an Analysis of the Metabolic and Bariatric Surgery Accreditation and Quality Improvement Program (MBSAQIP) Database
}

\author{
Shravan Leonard-Murali ${ }^{1} \cdot$ Hassan Nasser $^{1}$ (D) Tommy Ivanics $^{1} \cdot$ Dania Shakaroun $^{2} \cdot$ Jeffrey Genaw $^{1}$ \\ Published online: 9 October 2019 \\ (C) Springer Science+Business Media, LLC, part of Springer Nature 2019
}

\begin{abstract}
Background The safety and efficacy of laparoscopic sleeve gastrectomy (LSG) and laparoscopic Roux-en-Y gastric bypass (LRYGB) to treat obesity and associated comorbidities, including diabetes mellitus, is well established. As diabetes may add risk to the perioperative period, we sought to characterize perioperative outcomes of these surgical procedures in diabetic patients. Methods Using the Metabolic and Bariatric Surgery Accreditation and Quality Improvement Program (MBSAQIP) database, we identified patients who underwent LSG and LRYGB between 2015 and 2017, grouping by non-diabetics (NDM), non-insulindependent diabetics (NIDDM), and insulin-dependent diabetics (IDDM). Primary outcomes included serious adverse events, 30day readmission, 30-day reoperation, and 30-day mortality. Univariate and multivariable analyses were used to evaluate the outcome in each diabetic cohort.

Results Multivariable analysis of patients who underwent LSG (with NDM patients as reference) showed higher 30-day mortality $(\mathrm{NIDDM}$ AOR $=1.52, p=0.043 ;$ IDDM AOR $=1.91, p=0.007)$ and risk of serious adverse events $(\mathrm{NIDDM}$ AOR $=1.15$, $p<0.001$; IDDM AOR $=1.58, p<0.001)$ in the diabetic versus NDM groups. Multivariable analysis of patients who underwent LRYGB (with NDM patients as reference) showed higher risk of serious adverse events (NIDDM AOR = 1.09, $p=0.014$; IDDM $\mathrm{AOR}=1.43, p<0.001)$ in the diabetic versus NDM groups.

Conclusions Diabetics who underwent LSG and LRYGB had higher rates of several perioperative complications compared with non-diabetics. IDDM had a stronger association with several perioperative complications compared with NIDDM. This increase in morbidity and mortality is modest and should be weighed against the real benefits of bariatric surgery in patient with obesity and diabetes mellitus.
\end{abstract}

Keywords Diabetes mellitus $\cdot$ Sleeve gastrectomy $\cdot$ Gastric bypass $\cdot$ Outcomes $\cdot$ MBSAQIP

\section{Introduction}

The increasing prevalence of obesity has transformed surgical practice and the efficacy of bariatric surgery in aiding weight

This paper has not been previously presented or submitted for publication.

Hassan Nasser

hnasser2@hfhs.org

1 Department of Surgery, Henry Ford Hospital, 2799 W Grand Blvd, Detroit, MI 48202-2689, USA

2 Department of Internal Medicine, Henry Ford Hospital, Detroit, MI, USA loss $[1,2]$. The long-term health benefits of reducing weight have been well studied [3]. Remission of diabetes mellitus (DM) is often cited as an indication for bariatric surgery, with multiple studies indicating promising use of bariatric surgery for this purpose $[4,5]$. Nevertheless, there may be some concerns about the safety of bariatric surgery in diabetic patients since DM has been associated with increased perioperative complications including anastomotic leak as well as mortality $[6,7]$. This does not seem to be a consistent finding as some studies have failed to demonstrate that increased risk [8, 9]. Furthermore, there is paucity of literature on the differences in perioperative outcomes in diabetics who require insulin therapy compared with those who do not. Our aim was to evaluate perioperative outcomes in diabetic patients undergoing 
laparoscopic sleeve gastrectomy (LSG) and laparoscopic Roux-en-Y gastric bypass (LRYGB), the two most common bariatric procedures. We hypothesize that patients with DM will have a higher perioperative complication rate especially those requiring preoperative insulin therapy.

\section{Materials and Methods}

\section{Population and Study Groups}

This retrospective study used the Metabolic and Bariatric Surgery Accreditation and Quality Improvement Program (MBSAQIP) database which was used to identify patients who underwent LSG (Current Procedural Terminology code 43775) and LRYGB (Current Procedural Terminology code 43644) between January 1, 2015, and December 31, 2017. The MBSAQIP registry includes data from nationally accredited bariatric centers in North America. This database study was ruled exempt from Institutional Review Board approval at our institution.

Only procedures performed by conventional laparoscopic approach were included. Exclusion criteria included age less than 18 years, conversion/revision procedures, roboticassisted or open cases, unplanned conversion to alternative approaches, emergent cases, and cases with missing data. A total of 352,440 patients met the criteria above. There were 15,513 patients (4.4\%) with missing 30-day follow-up. Thus, the total number of patients analyzed was 336,927 . Patients were grouped based on diabetic status: non-diabetics (NDM); non-insulin-dependent DM (NIDDM), defined as those with a preoperative diagnosis of DM requiring therapy with a noninsulin anti-diabetic agent; and insulin-dependent DM (IDDM), defined as those with a preoperative diagnosis of DM requiring daily insulin therapy.

Covariates related to patient demographics included age, sex, race, preoperative body mass index (BMI) closest to surgery, and American Society of Anesthesiologists (ASA) class. Relevant patient comorbidities included in the analysis were coronary artery disease, hypertension, hyperlipidemia, smoking history, chronic obstructive pulmonary disease, oxygen dependence, obstructive sleep apnea, renal insufficiency, dialysis, deep vein thrombosis, pulmonary embolism, preoperative anticoagulation, inferior vena cava filter in place, steroid use, previous obesity/foregut surgery, use of an assistive device for ambulation, and functional status.

\section{Outcome Measures}

The primary outcomes of interest within 30 days of the operation were the occurrence of serious adverse events, readmission, reoperation, and mortality. Serious adverse events was a composite outcome that included at least one of the following: acute renal failure requiring dialysis, progressive renal insufficiency, cardiac arrest, myocardial infarction, unplanned admission to the intensive care unit, coma greater than $24 \mathrm{~h}$, cerebrovascular accident, ventilator use for more than $48 \mathrm{~h}$, unplanned intubation, pneumonia, surgical site infection (superficial, deep/incisional, or organ space), sepsis, septic shock, urinary tract infection, deep vein thrombosis, pulmonary embolism, anticoagulation for blood clot, bleeding requiring a transfusion, any intervention within 30 days, drain present at 30 days, and wound disruption.

Secondary outcomes evaluated included length of stay greater than 2 days, renal events (acute renal failure requiring dialysis or progressive renal insufficiency), cardiac events (cardiac arrest or myocardial infarction), respiratory complications (ventilator for more than $48 \mathrm{~h}$, unplanned intubation, or pneumonia), surgical site infection (superficial, deep/incisional, or organ space), septic events (sepsis or septic shock), urinary tract infections, venous thromboembolic (VTE) events (deep vein thrombosis, pulmonary embolism, or anticoagulation for presumed blood clot), transfusion for bleeding within $72 \mathrm{~h}$, and reintervention within 30 days. The causes of mortality for each patient cohort were reported.

Outcomes present at the time of surgery such as surgical site infections (superficial, deep/incisional, and organ space), sepsis, septic shock, pneumonia, urinary tract infections, and ventilator for more than $48 \mathrm{~h}$ were excluded from the analysis.

\section{Statistical Analysis}

Baseline demographics and comorbidities for each patient were reported using descriptive statistics expressed as counts and percentages for categorical data and mean \pm standard deviation for continuous data. Primary and secondary outcomes were reported for LSG and LRYGB separately. Univariate analysis used Pearson $X^{2}$ test or Fisher's exact test for categorical variables. Student's $t$ test and analysis of variance were used for continuous variables. Statistical significance was set to $p<0.05$. Multivariable logistic regression was performed for each outcome and adjusted odds ratios (AOR) were reported. We adjusted for age, sex, race, ASA class, and BMI. Since several comorbidities may have functioned as mediating variables between diabetes status and outcomes, we did not adjust for them as this would have removed any indirect effects of DM. All analyses were performed using IBM SPSS version 25 (Armonk, NY).

\section{Results}

\section{Patient Characteristics}

Of 336,927 patients, 73\% were NDM, 18\% NIDDM, and $9 \%$ IDDM (Table 1). The cases performed were 244,840 (72.7\%) LSG and 92,087 (27.3\%) LRYGB. A 
Table 1 Patient characteristics and comorbidities by diabetes mellitus status

\begin{tabular}{|c|c|c|c|c|c|}
\hline Patient characteristics & & $\operatorname{NDM}(n=247,554)$ & $\operatorname{NIDDM}(n=60,012)$ & $\operatorname{IDDM}(n=29,361)$ & $p$ value \\
\hline Age (years) & & $43.2 \pm 11.7$ & $48.4 \pm 11.4$ & $52.3 \pm 10.7$ & $<0.001$ \\
\hline \multirow[t]{2}{*}{ Sex } & Female & $202,573(81.8 \%)$ & $45,085(75.1 \%)$ & $19,714(67.1 \%)$ & \multirow[t]{2}{*}{$<0.00$} \\
\hline & Male & $44,981(18.2 \%)$ & $14,927(24.9 \%)$ & $9647(32.9 \%)$ & \\
\hline \multirow[t]{3}{*}{ Race } & White & $198,031(80.0 \%)$ & $47,540(79.2 \%)$ & $23,349(79.5 \%)$ & \multirow[t]{3}{*}{$<0.00$} \\
\hline & African American & $46,734(18.9 \%)$ & $11,515(19.2 \%)$ & $5519(18.8 \%)$ & \\
\hline & Other & $2789(1.13 \%)$ & $957(1.59 \%)$ & $493(1.68 \%)$ & \\
\hline \multirow[t]{3}{*}{ ASA } & $1-2$ & $65,855(26.6 \%)$ & $8491(14.2 \%)$ & $2532(8.62 \%)$ & \multirow[t]{3}{*}{$<0.00$} \\
\hline & 3 & $175,405(70.9 \%)$ & $48,891(81.5 \%)$ & $24,441(83.2 \%)$ & \\
\hline & $4-5$ & $6294(2.54 \%)$ & $2630(4.38 \%)$ & $2388(8.13 \%)$ & \\
\hline Body mass index $\left(\mathrm{kg} / \mathrm{m}^{2}\right)$ & & $45.4 \pm 7.83$ & $45.5 \pm 8.28$ & $45.2 \pm 8.12$ & $<0.001$ \\
\hline \multicolumn{6}{|l|}{ Comorbidities } \\
\hline \multicolumn{2}{|l|}{ Coronary artery disease } & $5227(2.11 \%)$ & $2690(4.48 \%)$ & $3290(11.2 \%)$ & $<0.001$ \\
\hline \multicolumn{2}{|l|}{ Hypertension } & $100,404(40.6 \%)$ & $42,018(70.0 \%)$ & $24,552(83.6 \%)$ & $<0.001$ \\
\hline \multicolumn{2}{|l|}{ Hyperlipidemia } & $37,493(15.2 \%)$ & $26,694(44.5 \%)$ & $18,979(64.6 \%)$ & $<0.001$ \\
\hline \multicolumn{2}{|l|}{ Smoker } & $21,985(8.88 \%)$ & $5097(8.49 \%)$ & $2253(7.67 \%)$ & $<0.001$ \\
\hline \multicolumn{2}{|l|}{ COPD } & $3199(1.29 \%)$ & $1579(2.63 \%)$ & $1256(4.28 \%)$ & $<0.001$ \\
\hline \multicolumn{2}{|l|}{ Oxygen dependent } & $1124(0.45 \%)$ & $618(1.03 \%)$ & $727(2.48 \%)$ & $<0.001$ \\
\hline \multicolumn{2}{|l|}{ Obstructive sleep apnea } & $86,149(34.8 \%)$ & $28,303(47.2 \%)$ & $15,705(53.5 \%)$ & $<0.001$ \\
\hline \multicolumn{2}{|l|}{ Renal insufficiency } & $742(0.30 \%)$ & $334(0.56 \%)$ & $1075(3.66 \%)$ & $<0.001$ \\
\hline \multicolumn{2}{|l|}{ Dialysis } & $434(0.18 \%)$ & $97(0.16 \%)$ & $440(1.50 \%)$ & $<0.001$ \\
\hline \multicolumn{2}{|l|}{ Deep vein thrombosis } & $3620(1.46 \%)$ & $1100(1.83 \%)$ & $835(2.84 \%)$ & $<0.001$ \\
\hline \multicolumn{2}{|l|}{ History of pulmonary embolism } & $2678(1.08 \%)$ & $836(1.39 \%)$ & $571(1.94 \%)$ & $<0.001$ \\
\hline \multicolumn{2}{|l|}{ Anticoagulation } & $5030(2.03 \%)$ & $2052(3.42 \%)$ & $1916(6.53 \%)$ & $<0.001$ \\
\hline \multicolumn{2}{|l|}{ Inferior vena cava filter } & $1654(0.67 \%)$ & $529(0.88 \%)$ & $396(1.35 \%)$ & $<0.001$ \\
\hline \multicolumn{2}{|l|}{ Venous stasis } & $2223(0.90 \%)$ & $812(1.35 \%)$ & $686(2.34 \%)$ & $<0.001$ \\
\hline \multicolumn{2}{|l|}{ Chronic steroid use } & $4072(1.64 \%)$ & $1077(1.79 \%)$ & $771(2.63 \%)$ & $<0.001$ \\
\hline \multicolumn{2}{|l|}{ GERD } & $73,323(29.6 \%)$ & $21,567(35.9 \%)$ & $11,767(40.1 \%)$ & $<0.001$ \\
\hline \multicolumn{2}{|l|}{ Previous foregut surgery } & $4145(1.67 \%)$ & $837(1.39 \%)$ & $460(1.57 \%)$ & $<0.001$ \\
\hline \multicolumn{2}{|l|}{ Use of assistive device } & $3034(1.23 \%)$ & $1209(2.01 \%)$ & $1200(4.09 \%)$ & $<0.001$ \\
\hline \multirow[t]{3}{*}{ Functional status } & Independent & $245,676(99.2 \%)$ & $59,354(98.9 \%)$ & $28,690(97.7 \%)$ & \multirow[t]{3}{*}{$<0.001$} \\
\hline & Partially dependent & $1097(0.44 \%)$ & $463(0.77 \%)$ & $539(1.84 \%)$ & \\
\hline & Totally dependent & $781(0.32 \%)$ & $195(0.32 \%)$ & $132(0.45 \%)$ & \\
\hline \multirow[t]{2}{*}{ Procedure performed } & LRYGB & $59,470(24.0 \%)$ & $19,598(32.7 \%)$ & $13,019(44.3 \%)$ & \multirow[t]{2}{*}{$<0.001$} \\
\hline & LSG & $188,084(76.0 \%)$ & $40,414(67.3 \%)$ & $16,342(55.7 \%)$ & \\
\hline
\end{tabular}

Abbreviations: ASA, American Society of Anesthesiologists; COPD, chronic obstructive pulmonary disease; GERD, gastroesophageal reflux disease; $N D M$, non-diabetics; $N I D D M$, non-insulin-dependent diabetics; IDDM, insulin-dependent diabetics; $L S G$, laparoscopic sleeve gastrectomy; $L R Y G B$, laparoscopic Roux-en-Y gastric bypass

Frequency and percentage listed for categorical variables

Mean \pm standard deviation listed for continuous variables

majority in each group were white women with a mean BMI of about $45 \mathrm{~kg} / \mathrm{m}^{2}$ and ASA class 3. Comorbidity rates significantly differed between groups, with the IDDM group showing the highest rates across almost all comorbidities, followed by NIDDM and NDM (Table 1). LRYGB was performed with increasing frequency (and LSG with decreasing frequency) in the diabetic groups (Table 1).

\section{Outcomes}

Rates of primary and secondary outcomes were highest in the IDDM group, followed by NIDDM then NDM (Table 2). For LSG, only VTE event rates did not differ based on diabetic status. For LRYGB, 30-day reoperation, septic events, urinary tract infections, and VTE events were not significantly different among the groups (Table 2). 


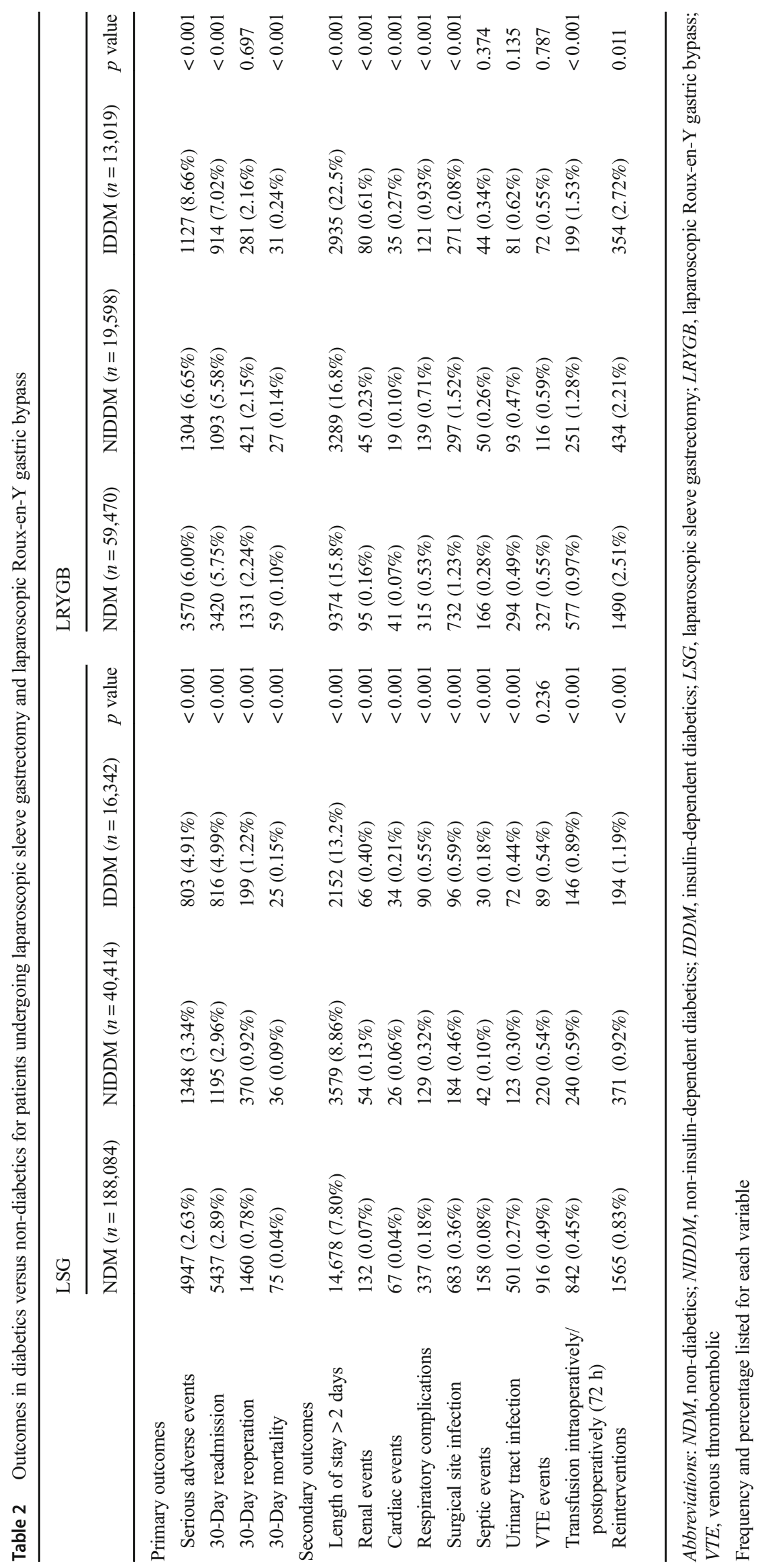


Table 3 Adjusted odds ratio for primary and secondary outcomes in patients undergoing laparoscopic sleeve gastrectomy and laparoscopic Roux-en-Y gastric bypass by diabetic status

\begin{tabular}{|c|c|c|c|c|c|c|c|c|}
\hline & \multicolumn{4}{|l|}{ LSG } & \multicolumn{4}{|l|}{ LRYGB } \\
\hline & \multicolumn{2}{|l|}{ NIDDM } & \multicolumn{2}{|l|}{ IDDM } & \multicolumn{2}{|l|}{ NIDDM } & \multicolumn{2}{|l|}{ IDDM } \\
\hline & AOR (95\% CI) & $p$ value & AOR $(95 \% \mathrm{CI})$ & $p$ value & AOR $(95 \% \mathrm{CI})$ & $p$ value & $\operatorname{AOR}(95 \% \mathrm{CI})$ & $p$ value \\
\hline \multicolumn{9}{|l|}{ Primary outcomes } \\
\hline \multirow[t]{2}{*}{ Serious adverse events } & \multirow[t]{2}{*}{$1.15(1.08-1.23)^{\mathrm{a}}$} & \multirow[t]{2}{*}{$<0.001$} & $1.58(1.46-1.71)^{\mathrm{a}}$ & $<0.001$ & \multirow[t]{2}{*}{$1.09(1.02-1.16)^{\mathrm{a}}$} & \multirow[t]{2}{*}{0.014} & $1.43(1.33-1.54)^{\mathrm{a}}$ & $<0.001$ \\
\hline & & & $1.38(1.26-1.51)^{\mathrm{b}}$ & $<0.001$ & & & $1.32(1.21-1.44)^{\mathrm{b}}$ & $<0.001$ \\
\hline \multirow[t]{2}{*}{ 30-Day readmission } & \multirow[t]{2}{*}{$1.00(0.94-1.07)^{\mathrm{a}}$} & \multirow[t]{2}{*}{0.989} & $1.69(1.56-1.83)^{\mathrm{a}}$ & $<0.001$ & \multirow[t]{2}{*}{$0.97(0.90-1.04)^{\mathrm{a}}$} & \multirow[t]{2}{*}{0.421} & $1.26(1.16-1.36)^{\mathrm{a}}$ & $<0.001$ \\
\hline & & & $1.68(1.53-1.85)^{\mathrm{b}}$ & $<0.001$ & & & $1.30(1.18-1.43)^{\mathrm{b}}$ & $<0.001$ \\
\hline \multirow[t]{2}{*}{ 30-Day reoperation } & \multirow[t]{2}{*}{$1.11(0.99-1.25)^{\mathrm{a}}$} & \multirow[t]{2}{*}{0.072} & $1.40(1.20-1.63)^{\mathrm{a}}$ & $<0.001$ & \multirow[t]{2}{*}{$0.91(0.82-1.02)^{\mathrm{a}}$} & \multirow[t]{2}{*}{0.116} & $0.88(0.77-1.01)^{\mathrm{a}}$ & 0.07 \\
\hline & & & $1.25(1.05-1.49)^{\mathrm{b}}$ & 0.013 & & & $0.97(0.83-1.13)^{\mathrm{b}}$ & 0.66 \\
\hline \multirow[t]{2}{*}{ 30-Day mortality } & \multirow[t]{2}{*}{$1.52(1.01-2.28)^{\mathrm{a}}$} & \multirow[t]{2}{*}{0.043} & $1.91(1.19-3.07)^{\mathrm{a}}$ & 0.007 & \multirow[t]{2}{*}{$0.98(0.61-1.55)^{\mathrm{a}}$} & \multirow[t]{2}{*}{0.918} & $1.32(0.83-2.09)^{\mathrm{a}}$ & 0.243 \\
\hline & & & $1.23(0.73-2.08)^{\mathrm{b}}$ & 0.432 & & & $1.33(0.78-2.25)^{\mathrm{b}}$ & 0.295 \\
\hline \multicolumn{9}{|l|}{ Secondary outcomes } \\
\hline Length of stay $>2$ days & $1.05(1.01-1.09)^{\mathrm{a}}$ & 0.023 & $1.52(1.45-1.60)^{\mathrm{a}}$ & $<0.001$ & $1.00(0.96-1.05)^{\mathrm{a}}$ & 0.944 & $1.38(1.32-1.45)^{\mathrm{a}}$ & $<0.001$ \\
\hline & & & $1.45(1.36-1.53)^{\mathrm{b}}$ & $<0.001$ & & & $1.39(1.32-1.47)^{\mathrm{b}}$ & $<0.001$ \\
\hline Renal events & $1.27(0.92-1.75)^{\mathrm{a}}$ & 0.152 & $2.72(1.98-3.72)^{\mathrm{a}}$ & $<0.001$ & $1.04(0.72-1.49)^{\mathrm{a}}$ & 0.844 & $2.22(1.61-3.05)^{\mathrm{a}}$ & $<0.001$ \\
\hline & & & $2.24(1.55-3.24)^{\mathrm{b}}$ & $<0.001$ & & & $2.25(1.55-3.26)^{\mathrm{b}}$ & $<0.001$ \\
\hline Cardiac events & $1.27(0.80-2.02)^{\mathrm{a}}$ & 0.305 & $3.12(2.01-4.84)^{\mathrm{a}}$ & $<0.001$ & $0.96(0.55-1.66)^{\mathrm{a}}$ & 0.876 & $1.97(1.21-3.20)^{\mathrm{a}}$ & 0.006 \\
\hline & & & $2.42(1.43-4.07)^{\mathrm{b}}$ & 0.001 & & & $2.05(1.16-3.62)^{\mathrm{b}}$ & 0.013 \\
\hline Respiratory complications & $1.41(1.15-1.73)^{\mathrm{a}}$ & 0.001 & $2.01(1.57-2.56)^{\mathrm{a}}$ & $<0.001$ & $1.14(0.93-1.40)^{\mathrm{a}}$ & 0.202 & $1.34(1.07-1.67)^{\mathrm{a}}$ & 0.01 \\
\hline & & & $1.41(1.07-1.87)^{\mathrm{b}}$ & 0.014 & & & $1.17(0.91-1.50)^{\mathrm{b}}$ & 0.216 \\
\hline Surgical site infections & $1.19(1.01-1.41)^{\mathrm{a}}$ & 0.038 & $1.51(1.21-1.88)^{\mathrm{a}}$ & $<0.001$ & $1.22(1.06-1.40)^{\mathrm{a}}$ & 0.005 & $1.71(1.48-1.90)^{\mathrm{a}}$ & $<0.001$ \\
\hline & & & $1.35(1.04-1.73)^{\mathrm{b}}$ & 0.022 & & & $1.45(1.22-1.71)^{\mathrm{b}}$ & $<0.001$ \\
\hline Septic events & $1.05(0.74-1.48)^{\mathrm{a}}$ & 0.786 & $1.61(1.07-2.42)^{\mathrm{a}}$ & 0.023 & $0.78(0.57-1.08)^{\mathrm{a}}$ & 0.133 & $0.94(0.66-1.33)^{\mathrm{a}}$ & 0.73 \\
\hline & & & $1.47(0.91-2.37)^{\mathrm{b}}$ & 0.119 & & & $1.25(0.82-1.88)^{\mathrm{b}}$ & 0.296 \\
\hline Urinary tract infection & $1.10(0.90-1.34)^{\mathrm{a}}$ & 0.362 & $1.60(1.24-2.07)^{\mathrm{a}}$ & $<0.001$ & $0.98(0.77-1.24)^{\mathrm{a}}$ & 0.841 & $1.33(1.02-1.72)^{\mathrm{a}}$ & 0.032 \\
\hline & & & $1.47(1.09-1.98)^{\mathrm{b}}$ & 0.012 & & & $1.33(0.98-1.81)^{\mathrm{b}}$ & 0.063 \\
\hline VTE events & $1.05(0.90-1.21)^{\mathrm{a}}$ & 0.569 & $0.99(0.79-1.24)^{\mathrm{a}}$ & 0.931 & $0.97(0.78-1.20)^{\mathrm{a}}$ & 0.765 & $0.84(0.65-1.10)^{\mathrm{a}}$ & 0.215 \\
\hline & & & $0.96(0.75-1.24)^{\mathrm{b}}$ & 0.771 & & & $0.87(0.65-1.18)^{\mathrm{b}}$ & 0.371 \\
\hline Transfusion intraoperative/ & $1.12(0.97-1.30)^{\mathrm{a}}$ & 0.121 & $1.45(1.21-1.75)^{\mathrm{a}}$ & $<0.001$ & $1.24(1.07-1.45)^{\mathrm{a}}$ & 0.005 & $1.41(1.19-1.67)^{\mathrm{a}}$ & $<0.001$ \\
\hline postoperative (72 h) & & & $1.30(1.05-1.60)^{\mathrm{b}}$ & 0.016 & & & $1.16(0.96-1.40)^{\mathrm{b}}$ & 0.133 \\
\hline Reintervention & $1.06(0.95-1.19)^{\mathrm{a}}$ & 0.313 & $1.33(1.14-1.55)^{\mathrm{a}}$ & $<0.001$ & $0.91(0.82-1.02)^{\mathrm{a}}$ & 0.098 & $1.16(1.03-1.32)^{\mathrm{a}}$ & 0.17 \\
\hline & & & $1.26(1.06-1.51)^{\mathrm{b}}$ & 0.011 & & & $1.27(1.10-1.47)^{\mathrm{b}}$ & 0.001 \\
\hline
\end{tabular}

Abbreviations: $A O R$, adjusted odds ratio; $C I$, confidence interval; NDM, non-diabetics; NIDDM, non-insulin-dependent diabetics; IDDM, insulindependent diabetics; $L S G$, laparoscopic sleeve gastrectomy; $L R Y G B$, laparoscopic Roux-en-Y gastric bypass; VTE, venous thromboembolic

Adjusted odds ratios with $95 \%$ confidence intervals listed for each variable

${ }^{\text {a }}$ Reference group of NDM

${ }^{\mathrm{b}}$ Reference group of NIDDM

Multivariable analysis of patients who underwent LSG (with NDM patients as reference) showed higher 30-day mortality (NIDDM AOR $=1.52, p=0.043$; IDDM AOR $=$ $1.91, p=0.007)$ and risk of serious adverse events $(\mathrm{NIDDM}$ AOR $=1.15, p<0.001 ;$ IDDM AOR $=1.58$, $p<0.001$ ) in the diabetic versus NDM groups (Table 3 ). Multivariable analysis of patients who underwent LRYGB (with NDM patients as reference) showed higher risk of serious adverse events (NIDDM AOR $=1.09, p=0.014$; IDDM AOR $=1.43, p<0.001)$ in the diabetic versus NDM groups. In all diabetic cohorts except NIDDM in the LRYGB group, pulmonary embolism was the most common reported cause of the death followed by respiratory failure and infectious complications (Table 4). Infectious complications were the most common cause of death in the LRYGB NIDDM group (Table 4). 
Table 4 Cause of mortality in each diabetic patient cohort for laparoscopic sleeve gastrectomy and Roux-en-Y gastric bypass

\begin{tabular}{|c|c|c|c|c|c|c|}
\hline \multirow[t]{2}{*}{ Cause of death } & \multicolumn{3}{|l|}{ LSG } & \multicolumn{3}{|l|}{ LRYGB } \\
\hline & $\operatorname{NDM}(n=75)$ & $\operatorname{NIDDM}(n=36)$ & $\operatorname{IDDM}(n=25)$ & $\operatorname{NDM}(n=59)$ & $\operatorname{NIDDM}(n=27)$ & $\operatorname{IDDM}(n=31)$ \\
\hline Pulmonary embolism & $18(24.0 \%)$ & $6(16.7 \%)$ & $5(20.0 \%)$ & $9(15.3 \%)$ & $1(3.7 \%)$ & $6(19.4 \%)$ \\
\hline Respiratory failure & $9(12.0 \%)$ & $4(11.1 \%)$ & $2(8.0 \%)$ & $8(13.6 \%)$ & $2(7.4 \%)$ & $4(12.9 \%)$ \\
\hline Infectious complications & $5(6.7 \%)$ & $0(0.0 \%)$ & $2(8.0 \%)$ & $4(6.8 \%)$ & $3(11.1 \%)$ & $0(0.0 \%)$ \\
\hline Anastomotic/staple line leak & $6(8.0 \%)$ & $0(0.0 \%)$ & $1(4.0 \%)$ & $1(1.7 \%)$ & $0(0.0 \%)$ & $2(6.5 \%)$ \\
\hline Intestinal obstruction & $0(0.0 \%)$ & $0(0.0 \%)$ & $0(0.0 \%)$ & $3(5.1 \%)$ & $2(7.4 \%)$ & $0(0.0 \%)$ \\
\hline Bleeding & $1(1.3 \%)$ & $3(8.3 \%)$ & $0(0.0 \%)$ & $1(1.7 \%)$ & $2(7.4 \%)$ & $2(6.5 \%)$ \\
\hline Other & $36(48.0 \%)$ & $23(63.9 \%)$ & $15(60.0 \%)$ & $33(55.9 \%)$ & $17(63.0 \%)$ & $17(54.8 \%)$ \\
\hline
\end{tabular}

Abbreviations: $N D M$, non-diabetics; $N I D D M$, non-insulin-dependent diabetics; IDDM, insulin-dependent diabetics; $L S G$, laparoscopic sleeve gastrectomy; $L R Y G B$, laparoscopic Roux-en-Y gastric bypass

Frequency and percentage listed for each variable

Overall, IDDM patients had statistically higher odds for 13 of the 14 outcome measures when undergoing LSG and for 9 of 14 measures when undergoing LRYGB (Table 3). The NIDDM patients showed statistically higher odds for 6 of 14 measures for LSG and 3 of 14 measures for LRYGB (Table 3). When using NIDDM as the reference group, the IDDM patients showed statistically higher odds for 11 of 14 outcome measures when undergoing LSG and for 7 of 14 for LRYGB (Table 3).

\section{Discussion}

This study aimed to compare the perioperative outcomes in diabetic patients undergoing LSG and LRYGB. Patients were stratified by insulin requirement into NIDDM and IDDM. The goal was to evaluate outcomes in IDDM. We hypothesized that these patients will have a higher complication rate as diabetic patients on insulin tend to have a longer duration of disease and, hence, higher rates of end organ damage. Our study found a higher 30-day perioperative morbidity in patients with diabetes compared with non-diabetics undergoing LSG or LRYGB. This was demonstrated independently in the NIDDM and IDDM groups. Patients with IDDM showed higher rates and higher adjusted odds for serious adverse events, readmission, length of stay, renal events, cardiac events, and surgical site infection for both LSG and LRYGB when compared with those of the NIDDM and NDM groups. As for mortality, IDDM and NIDDM patients had higher 30day mortality when undergoing LSG but not LRYGB. This is, to our knowledge, the largest study comparing differences in perioperative complications between NIDDM and IDDM patients in bariatric surgery patients.

Although perioperative risk associated with DM has been studied in other surgical populations, differences between NIDDM and IDDM patients are not clearly defined [10]. In a study on perioperative outcomes from the Michigan Surgical Quality Collaborative on 177,430 patients, Serio et al. found increased perioperative morbidity in general and vascular surgery patients with IDDM compared with that in NIDDM and NDM [11]. However, their study did not show an increased risk of postoperative complications in NDDM patients [11]. Similar to our findings, Steele et al. demonstrated in their study on 22,288 bariatric cases an increased risk of cardiac, infectious, and renal complications in diabetic patients although patients were not stratified based on insulin requirement status [12]. Some studies have failed to demonstrate increased complications with LSG and LRYGB in diabetics $[8,9]$. Nevertheless, these studies were smaller and likely underpowered.

Development of DM is a well-known side effect of obesity, with rates of both conditions rising every year in the USA according to the Centers for Disease Control and Prevention [1, 13]. For patients with obesity and $\mathrm{DM}$, the comorbidities can be numerous and life-altering. The use of bariatric surgery for weight loss and reduction in obesity-related DM over a short period of time has been proven [14-16]. Several studies have shown data supporting the use of bariatric surgery for remission of DM [17, 18]. More recent studies clarified that bariatric surgery benefits specifically those patients with type 2 DM with more preoperative beta cell function [19], both when measured in terms of serum insulin levels and as preoperative insulin requirements [20]. However, the benefits appear to be mitigated in the obese with type 1 diabetes [21], who almost universally require daily insulin supplementation.

Zaman et al. investigated perioperative glucose control in diabetics undergoing bariatric surgery and found that optimal control was predictive of long-term diabetes remission [22]. It is unclear whether this was due to any physiological events perioperatively or simply due to worse 
disease manifesting as uncontrolled perioperative glucose levels. Leonetti et al. investigated the effects of specific preoperative diets in patients before bariatric surgery [23]. Although results were inconclusive, positive or negative results could help answer whether perioperative glucose control has more to do with the perioperative adverse outcomes or another physiological mechanism is at play in diabetic patients. Nonetheless, bariatric surgery should continue to be offered to those with DM, but with a heightened awareness of potential perioperative complications as indicated by our study. Preoperative optimization of diabetes status may be of benefit to these patients to prevent adverse outcomes.

Our study had several limitations. The MBSAQIP database does not record data on perioperative blood glucose control which limits our ability to adjust for diabetic control, number of diabetic medications, or amount of insulin used. It may be possible that poor perioperative glucose control contributed to worse outcomes in IDDM. However, if this was the mechanism by which the perioperative risks are increased it would be helpful to identify and evaluate in future studies since this is an opportunity to intervene and prevent complications associated with DM. Moreover, patients who were not offered surgery due to poor preoperative glucose control were not included in the analysis as they never received surgery. This creates a selection bias in the study and may underestimate the perioperative risk involved. Furthermore, the database only includes 30-day postoperative data. Therefore, no longterm conclusion regarding complications or remission of diabetes can be drawn.

\section{Conclusions}

Perioperative morbidity in patients with DM undergoing bariatric surgery was higher than that in NDM patients, and 30day mortality was higher in those undergoing LSG specifically. Patients with IDDM had increased risks of perioperative complications versus those with NIDDM. These observed increases in morbidity and mortality are real but modest in size and have to be considered against the real benefits of bariatric surgery in patients with obesity and DM.

\section{Compliance with Ethical Standards}

Conflict of Interest The authors declare that they have no conflict of interest.

Ethical Approval This article does not contain any studies with human participants or animals performed by any of the authors.

Informed Consent For this type of study, formal consent is not required.

\section{References}

1. Centers for Disease Control and Prevention. Adult obesity facts. 2018. Available at: https://www.cdc.gov/obesity/data/adult.html. Accessed 01 Jun 2019.

2. Nickel F, Schmidt L, Bruckner T, et al. Influence of bariatric surgery on quality of life, body image, and general self-efficacy within 6 and 24 months - a prospective cohort study. Surg Obes Relat Dis. 2017;13(2):313-9.

3. Sjostrom L. Review of the key results from the Swedish Obese Subjects (SOS) trial - a prospective controlled intervention study of bariatric surgery. J Intern Med. 2012;273:219-34. https://doi.org/ 10.1111/joim.12012.

4. Yska JP, van Roon EN, de Boer A, et al. Remission of type 2 diabetes mellitus in patients after different types of bariatric surgery a population-based cohort study in the United Kingdom. JAMA Surg. 2015;150(12):1126-33.

5. Schauer DP, Arterburn DE, Livingston EH, et al. Impact of bariatric surgery on life expectancy in severely obese patients with diabetes: a decision analysis. Ann Surg. 2015;261(5):914-9.

6. Lin X, Li J, Chen W, et al. Diabetes and risk factors of anastomotic leakage after gastrointestinal surgery. J Surg Res. 2015;196(2):294 301.

7. Tao W, Plecka-Ostlund M, Lu Y, et al. Causes and risk factors for mortality within 1 year after obesity surgery in a population-based cohort study. Surg Obes Relat Dis. 2015;11(2):399-405.

8. Rawlins L, Rawlins MP, Brown CC, et al. Effect of elevated hemoglobin A1c in diabetic patients on complication rated after Rouxen-Y gastric bypass. Surg Obes Relat Dis. 2013;9(5):749-52.

9. Creange C, Sethi M, Fielding G, et al. The safety of laparoscopic sleeve gastrectomy among diabetic patients. Surg Endosc. 2017;31(2):907-911.10.

10. Ata A, Valerian BT, Lee EC, et al. The effect of diabetes mellitus on surgical site infections after colorectal and noncolorectal general surgical operations. Am Surg. 2010;76(7):697-702.

11. Serio S, Clements JM, Grauf D, et al. Outcomes of diabetic and nondiabetic patients undergoing general and vascular surgery. ISRN Surg. 2013;2013:963930.

12. Steele KE, Prokopowicz GP, Chang HY, et al. Risk of complications after bariatric surgery among individuals with and without type 2 diabetes mellitus. Surg Obes Relat Dis. 2012;8(3):305-30.

13. Centers for Disease Control and Prevention. New CDC report: more than 100 million Americans have diabetes or prediabetes. 2017. Available at: https://www.cdc.gov/media/releases/2017/ p0718-diabetes-report.html. Accessed 4 June 2019.

14. Kizy S, Jahansouz C, Downey MC, et al. National trends in bariatric surgery 2012-2015: demographics, procedure selection, readmissions, and cost. Obes Surg. 2017;27(11):2933-9.

15. Sun S, Borisenko O, Spelman T, et al. Patient characteristics, procedural and safety outcomes of bariatric surgery in England: a retrospective cohort study-2006-2012. Obes Surg. 2018;28(4):1098108.

16. Welbourn R, Pournaras DJ, Dixon J, et al. Bariatric surgery worldwide: baseline demographic description and one-year outcomes from the Second IFSO Global Registry Report 2013-2015. Obes Surg. 2018;28(2):313-22.

17. Scheen AJ, de Flines J, de Roover A, et al. Bariatric surgery in patients with type 2 diabetes: benefits, risks, indications and perspectives. Diabetes Metab. 2009;35(6 Pt 2):537-43.

18. Liakopoulos V, Franzén S, Svensson AM, et al. Pros and cons of gastric bypass surgery in individuals with obesity and type 2 diabetes: nationwide, matched, observational cohort study. BMJ Open. 2019;9(1):e023882. 
19. Souteiro P, Belo S, Neves JS, et al. Preoperative beta cell function is predictive of diabetes remission after bariatric surgery. Obes Surg. 2017;27(2):288-94.

20. Hariri K, Guevara D, Jayaram A, et al. Preoperative insulin therapy as a marker for type 2 diabetes remission in obese patients after bariatric surgery. Surg Obes Relat Dis. 2018;14(3):332-7.

21. Vilarrasa N, Rubio MA, Miñambres I, et al. Long-term outcomes in patients with morbid obesity and type 1 diabetes undergoing bariatric surgery. Obes Surg. 2017;27(4):856-63.
22. Zaman JA, Shah N, Leverson GE, et al. The effects of optimal perioperative glucose control on morbidly obese patients undergoing bariatric surgery. Surg Endosc. 2017;31(3):1407-13.

23. Leonetti F, Campanile FC, Coccia F, et al. Very low-carbohydrate ketogenic diet before bariatric surgery: prospective evaluation of a sequential diet. Obes Surg. 2015;25(1):64-71.

Publisher's Note Springer Nature remains neutral with regard to jurisdictional claims in published maps and institutional affiliations. 